\title{
Arduino Devreleri için Kod Üretme ve Veri İşleme Uygulaması Tasarımı
}

\author{
Volkan ÇAVUŞ $^{1} \stackrel{\&}{ }$, Resul TUNA ${ }^{1}$, İsmail Umut DURAN ${ }^{1}$ \\ ${ }^{1}$ Meslek Yüksekokulu, Sinop Üniversitesi, Sinop, Türkiye \\ $\triangle$ : vcavus@sinop.edu.tr
}

Geliş (Received): 10.05.2017

Düzeltme (Revision):26.05.2017

Kabul (Accepted): 01.06.2017

\section{ÖZ}

Sensör kullanılarak yapılan uygulama veya deneysel çalışmalarda alınan ölçümlerin bilgisayara aktarılması için veri işleme kartlarına ihtiyaç duyulmaktadır. Bu tür çalışmalarda kullanım kolaylığı açısından en çok tercih edilen platformlardan birisi de Arduino'dur. Açık kaynaklı bir geliştirme platformu olan Arduino'nun dijital ve analog girişleri sayesinde veriler okunup işlenebilmektedir. Bu çalışmada, bilgisayar ortamında $\mathrm{C \#}$ programlama dili kullanılarak geliştirilen uygulama sayesinde Arduino'ya bağlanan farklı sensörler içerisinden istenilen sensörler seçilebilmektedir. Seçilen bu sensörleri kullanmak için gerekli Arduino kodu herhangi bir programlama bilgisine ihtiyaç duyulmadan oluşturulabilmektedir. Arduino üzerindeki sensörlerden gelen veriler belirli zaman aralığında veya anlık olarak kaydedilebilmektedir. Kaydedilen verilerin, istenilen periyotlarda ve özelliklerde grafikleri elde edilebilmekte ve raporlama yapılması sağlanabilmektedir. Bu uygulama sayesinde Arduino programlamayı bilmeyen ve devre üzerinde veri okumakta zorlanan araştırmacıların deneylerini rahatlıkla yapabildikleri gözlenmiştir. Özellikle temel bilimler ve mühendislik alanlarındaki araştırmacıların bu uygulamayı kullanarak bilimsel çalışmalarını ihtiyaçları olmayan bilgilere gereksinim duymadan kolay bir şekilde yapabildikleri tespit edilmiştir.

Anahtar Kelimeler: Arduino, C\#, Uygulama Arayüzü.

\section{Code Generation and Data Process Application Desing for Arduino Cicuits}

\begin{abstract}
Data processing cards are needed for transferring the sensor measurements from applications or experimental works to computers. Ardunio is the one of those platforms which is preferred in this kind of works due to its ease of use. The digital and analog inputs of Arduino, which is an open source development platform, allow to read and process the data. In this work, the desired sensors can be chosen amongst the sensors connected to Arduino via the application developed using C\# programming language in computer environment. Required Arduino Code in order to use selected sensors can be generated without any programming knowledge. Data come from the sensors over Arduino can be recorded in a specified time interval or instantly. Also, the plots of recorded data can be easily obtained and reported in the desired periods and features. Through with this application, it is observed the researchers, who does not know Arduino Programming and have difficulty to read data on circuits, can do experiments easily. Especially, researchers in the fields of basic science and engineering are identified that they can do their scientific studies by using this application easily without the need for information that they do not need to.
\end{abstract}

Keywords: Application Interface, Arduino, C\#.

\section{GíRiş}

Günümüzde bilgisayar alanında üzerinde en çok araştırma yapılan ve en hızlı gelişen konulardan biri olan sensörler, fiziksel veya kimyasal büyüklükleri elektriksel büyüklüklere çevirerek kullanılabilir formata dönüştürmektedirler [1]. Sensörler kablosuz iletişim, sinyal algılama, alınan sinyali işleme ve yayma gibi yeteneklere sahiptir [2]. Sensörler günümüzde sağlık, askeri ve endüstriyel uygulamalarda olmak üzere birçok alanda kullanılmaktadır. Sensörler kullanılarak yapılan uygulama veya deneysel çalışmalarda alınan ölçümlerin bilgisayara aktarılması için veri toplama kartlarına ihtiyaç duyulmaktadır [3]. Bu tür çalışmalarda kullanım kolaylığı açısından en çok tercih edilen platformlardan birisi de Arduino'dur.

Hastaların kalp atış hızını uzaktan izleme [4], tank namlusu stabilizasyon sistemi [5], Kaotik mobil haberleşme sistemi [6], DC motor hiz kontrol sistemi [7], yangın alarm ve görüntüleme sistemi [8], üç eksenli plaket çizim robotu [9] gibi pek çok çalışmada Arduino kullanılmıştır.

$\mathrm{Bu}$ çalışmada, yapılabilecek bir uygulama veya deneysel çalışma için kullanılan sensörlerin Arduino üzerinde çalışması için gerekli koda, sensörlerden alınan bilgilerin okunması, raporlanma ve grafiklere 
dönüştürülmesi için $\mathrm{C \#}$ programlama dili yardımıyla kullanıcı erişimli bir ara yüz gerçekleştirilmiştir

\section{MATERYAL ve METOD}

\section{Arduino Uno}

Mikrodenetleyici, içerisinde bellek, giriş-çıkış ve mikro işlemci üniteleri bulunduran entegre hali getirilmiş programlanabilen elemanlardır [10].

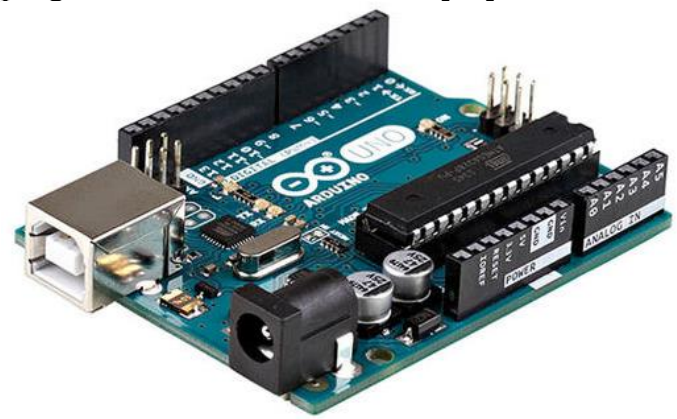

Şekil 1'de gösterilen Arduino Uno, üzerinde Atmega328 mikrodenetleyici, güç regülatörü, USB bağlantı gibi bileşenler bulunduran, seri-USB dönüştürücü sayesinde hem seri port üzerinden iletişim kurabilen hem de programlanabilmektedir. [11]. Mikrodenetleyiciler bir bilgisayarın yaptığı tüm işleri yapabilmektedir. Giriş çıkış kartı ve Processing/Wiring dilinin bir uygulamasını içeren açık kaynak geliştirme platformu olan [12] Arduino'nun, dijital ve analog girişleri sayesinde veriler okunup işlenebilmektedir [13].

Arduino programlamak için kullanılan arayüz Şekil 2'de gösterilmiştir. $\mathrm{Bu}$ arayüzü kullanarak arduino ile yapılmak istenen işe ait program kodları yazilır. Arduinoda kullanilan dil Arduinonunda temelini oluşturan processing programlama dilidir. $\mathrm{Bu}$ dil $\mathrm{C}++$ ve C alt yapısına sahiptir [11].

Şekil 1. Arduino elektronik kart

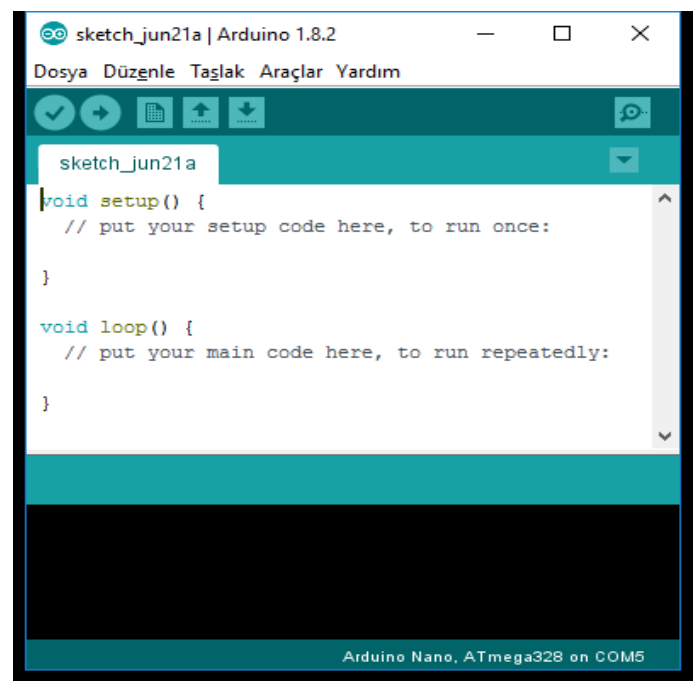

Şekil 2. Arduino programlama arayüzü

Temel olarak arduino programlamada iki fonksiyon kullanılmaktadır. setup() fonksiyonu arduino çalışmaya başladığı anda ilk çalıştırılan fonksiyondur ve bir kere çalışır. Program için gerekli ayarların olduğu kod bloğudur. loop() fonksiyonu setup fonksiyonundan sonra çalışmaya başlar ve Arduino çalıştığı sürece tekrar edilir. Bu fonksiyon asıl işin yapıldığı kod bloğudur.

Arduino ile yapılan uygulamalarda bu programlama bilgisi gereklidir. Ancak yapmış olduğumuz çalışma ile bu programlama bilgisine hiç sahip olmadan ve hiç kod yazmadan istenilen uygulamalar rahatlıkla tasarlanabilmektedir.

\section{Uygulama Arayüzü}

Geliştirilen uygulama arayüzü üç aşamadan oluşmaktadır. Birinci aşama olan sensör seçimi ve
Arduino kodu oluşturma ekran görüntüsü Şekil 3'de gösterilmiştir. 1 numaralı bölümde çalışmada veya uygulamada kullanılacak sensörlerin seçimi gerçekleştirilir. Seçilen sensörlerin Arduino üzerindeki pin bağlantı numaraları 2 numaralı bölümde belirlenir. Bu iki bölüm sayesinde Arduino üzerinde kullanılacak sensör ve bağlantı bilgileri arayüz ekranında tanımlanır. Ayarları yapılan devrenin sensör ve bağlantı pin bilgilerine göre otomatik olarak 3 numaralı bölümde Arduino kodu oluşturulur. Uygulama sayesinde elde edilen kod, Arduino programlama editörü [14] sayesinde Arduino'ya yüklenir ve hazırlanan devre çalışır duruma getirilir. 


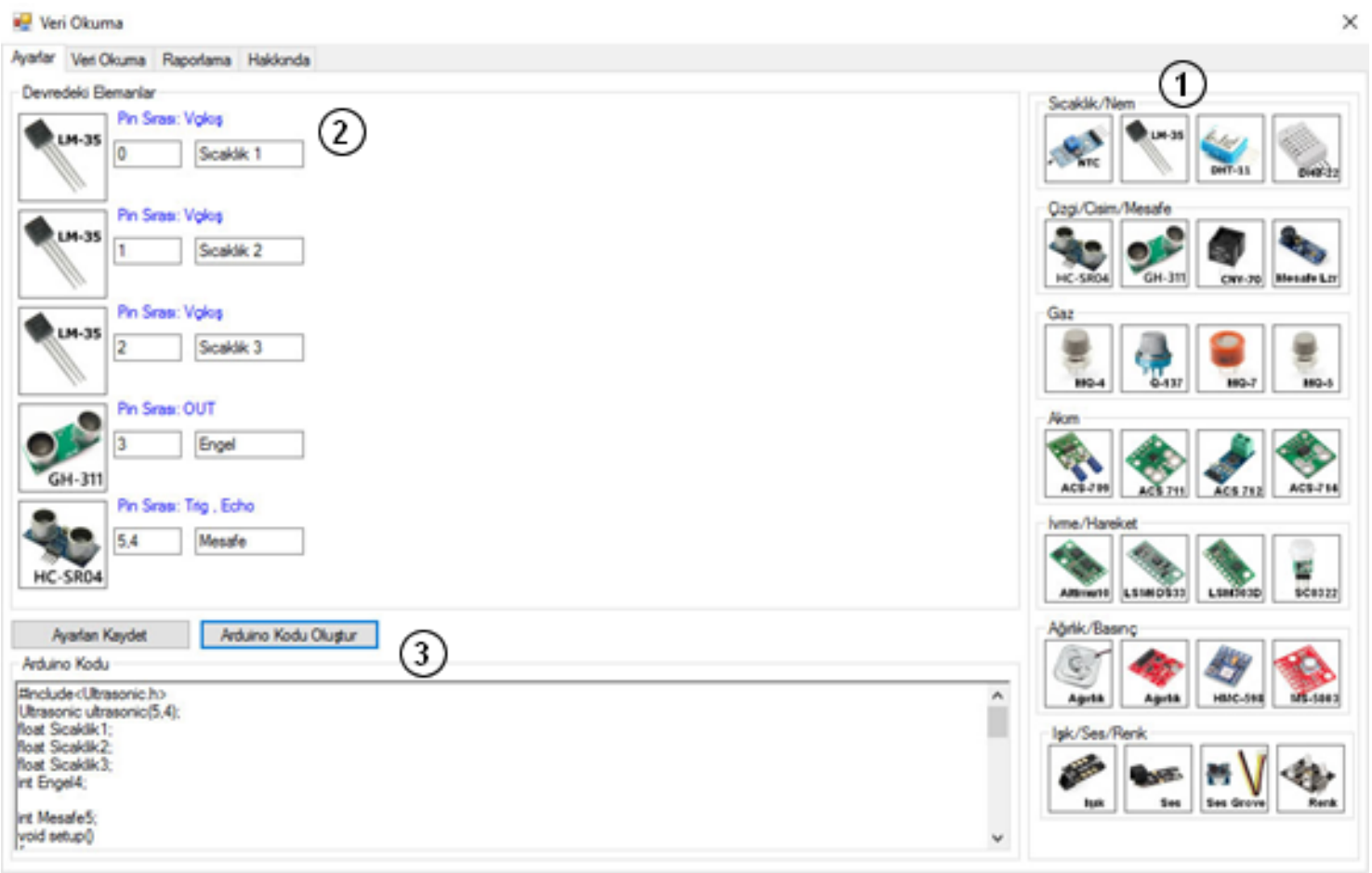

Şekil 3. Sensör seçimi ve arduino kod oluşturma ekranı

İkinci aşama olan veri okuma ekran görüntüsü Şekil 4'te gösterilmiştir. 4 numara ile gösterilmiş bölümde Arduino'nun bilgisayar bağlantısı gerçekleştirilir. Bilgisayar bağlantısı gerçekleştirildikten sonra 5 numaralı bölümden sensörlerden gelen verileri okuma işlemi başlatılır. Veri okuma işlemi anlık veya ileri tarih ve saat aralığında olmak üzere iki farklı şekilde gerçekleştirilir. Veri okuma işlemi başladığında okunan veriler 6 numaralı bölümdeki tabloda anlık olarak gösterilir ve okunan veriler veri tabanına otomatik olarak kaydedilir.

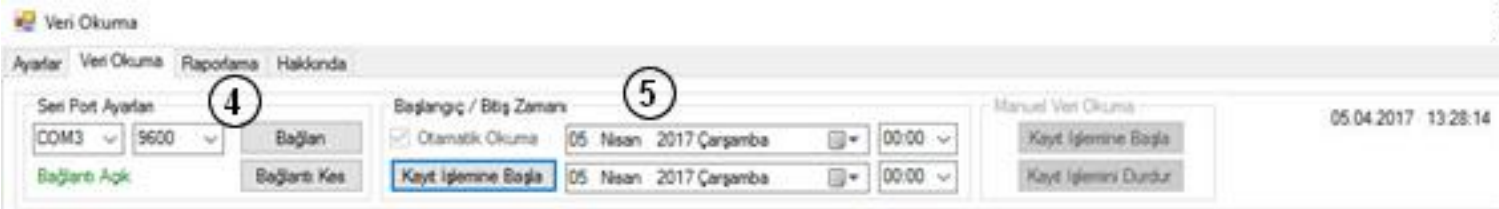

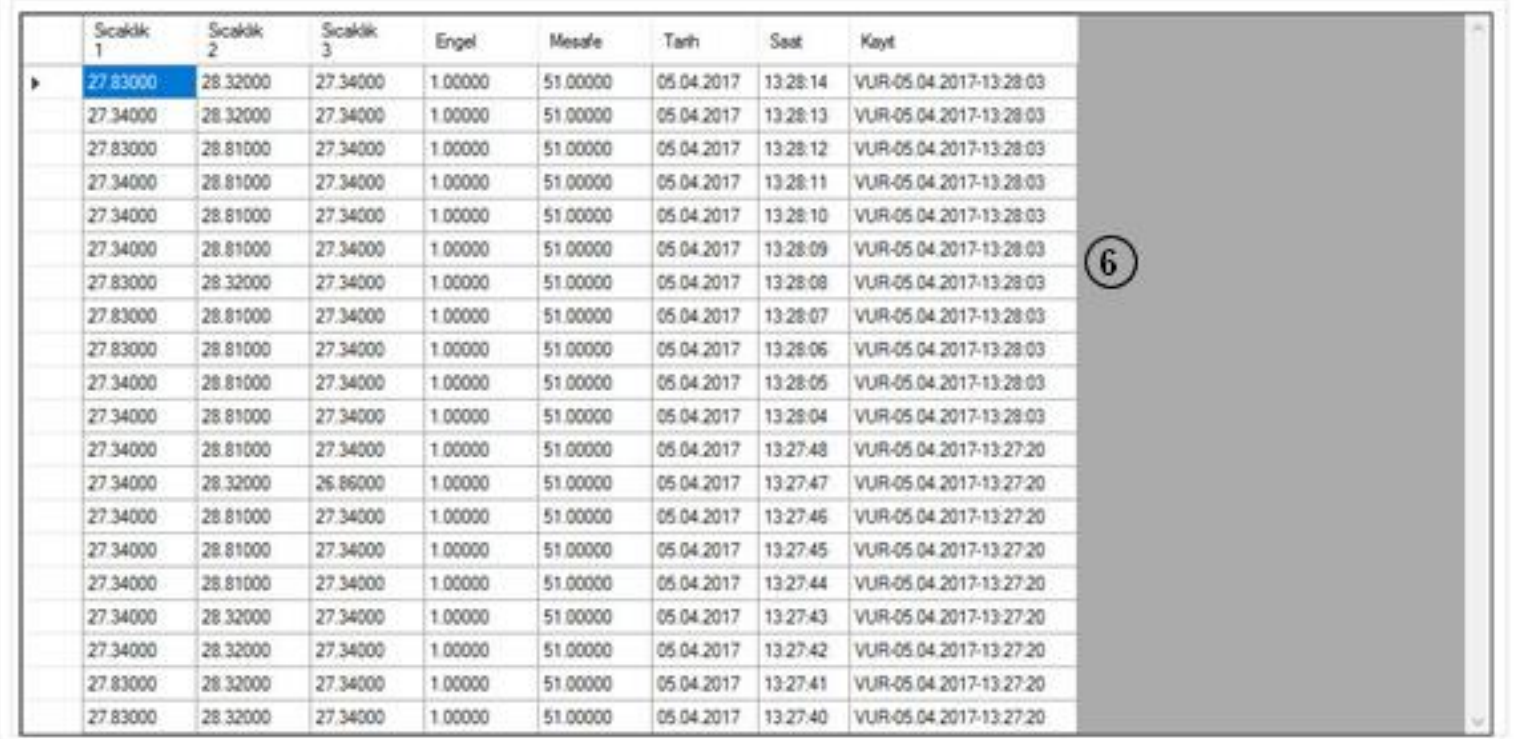

Şekil 4. Veri okuma ekranı 
Üçüncü aşama raporlama bölümü ekran görüntüsü Şekil 5'te gösterilmiştir. Tüm yapılan deneysel çalışmalar kayıt altında tutulduğundan 7 numaralı bölümden hangi kayıt ile ilgili işlem yapılmak isteniyorsa seçilir. 8 numaralı bölümden Excel'e aktarılacak veriler seçilerek aktarma işlemi gerçekleştirilir, Grafiği oluşturulmak istenen veri, 9 numaralı bölümden seçilerek grafiği oluşturulur.

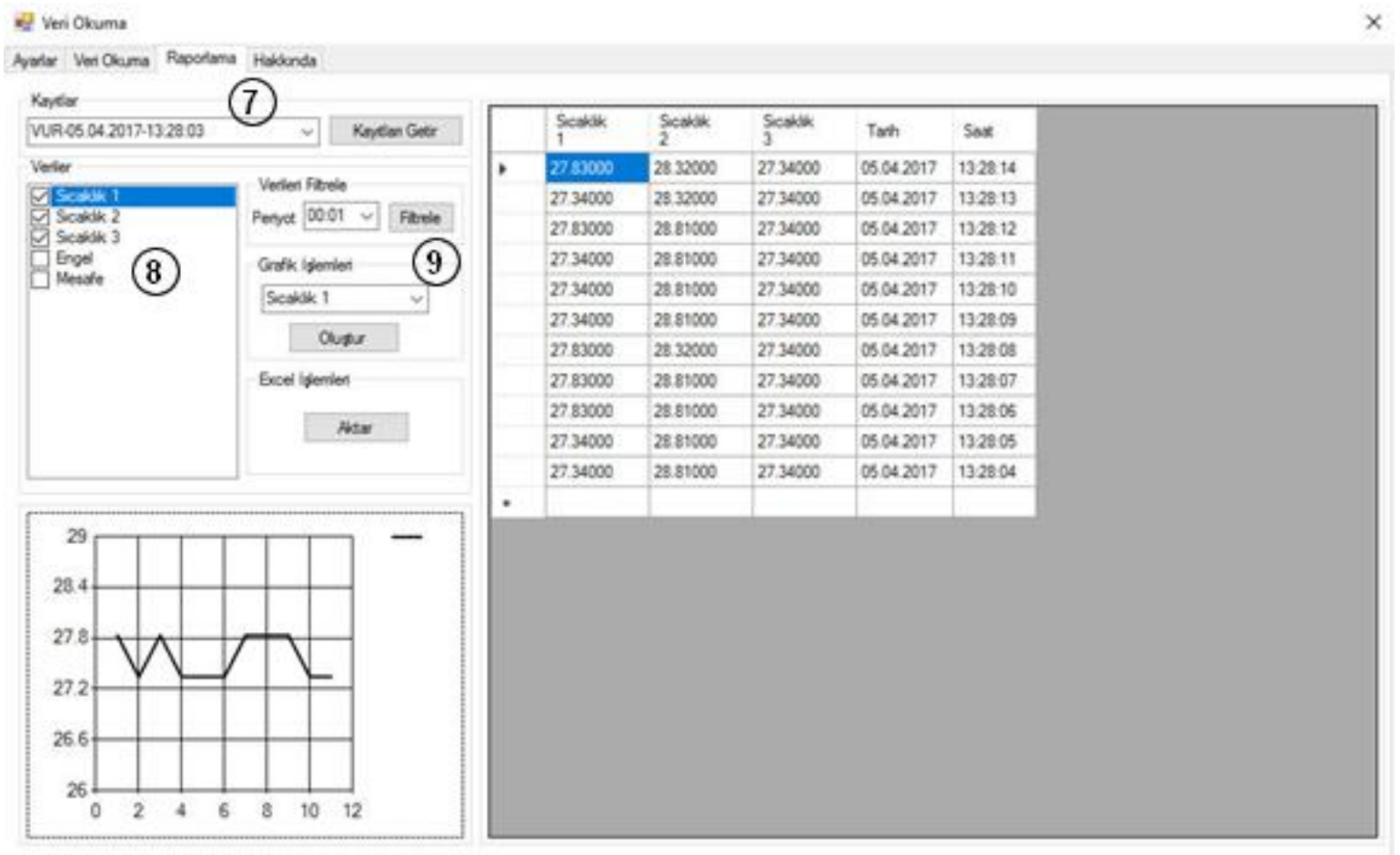

Şekil 5. Raporlama ekranı

\section{SONUÇ}

Bu uygulama sayesinde;

- Programlama bilgisine sahip olmadan Arduino kodlama yapabilme,

- Sensörlerden kolaylıkla veri okuma ve kayıt altında tutma,

- Kayıt altında tutulan verileri raporlama ve grafiklere dönüştürme,

- Bilgisayar başında olmadan ileri tarih ve saat aralığında veri okuma

gibi birçok işlemi rahatlıkla yapılabildiği gözlenmiştir

\section{KAYNAKÇA}

[1] Tekin A. B., Demirel C., Örün C.. Tarımda kablosuz Ağlar. Ege Üniversitesi, Ziraat Fakültesi, Tarım Makinaları Bölümü, İzmir, 2011.

[2] Kalaycı T. E. Kablosuz sensör ağlar ve uygulamaları. Akademik Bilişim Konferans1, Şanlıurfa. 2009.

[3] Güllü A., Arda M., Kuş̧̧u H. Servo Sistemlerin Matlab Uzerinden Gömülü Sistemler ile PID Kontrolü. 16. Ulusal Makina Teorisi Sempozyumu, 2013.

[4] Kemis H., Bruce N., Ping W., Antonio T., Gook L. B., Lee, H. J. Healthcare monitoring application in ubiquitous sensor network: Design and implementation based on pulse sensor with arduino. In Information Science and Service Science and Data
Mining (ISSDM), 6th International Conference on New Trends in p. 34-38, 2012.

[5] Songül S. Tank Namlusu Stabilizasyon Sisteminin Arduino ile uygulanması ve Deneysel Düzeneğin Hazırlanması, Trakya Üniv., Fen Bilimleri Enstitüsü, 2014

[6] Abdulrahman B. A. Arduino kullanılarak Kaotik Mobil Haberleşme Sistemi Tasarımı, Yüzüncü Yıl Üniversitesi, Fen Bilimleri Enstitüsü, 2016.

[7] Rai N., Rai B. Neural network based closed loop speed control of DC motor using arduino uno International Journal of Engineering Trends and Technology, 4, 137-140, 2013.

[8] Bahrudin M. S. B., Kassim R. A., Buniyamin N. Development of Fire Alarm System using Raspberry $\mathrm{Pi}$ and Arduino Uno. In Electrical, Electronics and System Engineering (ICEESE), International Conference on p. 43-48, 2013

[9] Çavuş V., Tuna, R. Duran İ.U. İki Boyutlu Devre Resminin Tasarlanan Uc Eksenli Bir Platform İle Plaket Üzerine Çizimi, 5. Uluslararası Meslek Yüksekokulları Sempozyumu, sy.179-182, 2016.

[10] K1liçarslan S. Mikrodenetleyici Temelli PLC'ler için Programlama Yazılımının Gerçekleștirilmesi, Gaziosmanpaşa Üniversitesi, Fen Bilimleri Enstitüsü, 2014.

[11] Taşdemir C. Arduino. İstanbul: Dikeyeksen Yayın Dağıtım, 2014.

[12] Ersin Ç. Arduino Mikrodenetleyici ve Güneş Enerjisi ile Calısan Otomatik Bitki Sulama Sistemi, Süleyman Demirel Üniversitesi, Fen Bilimleri Enstitüsü, 2015.

[13] www.arduinoturkiye.com, (Erișim tarihi: 09.03.2017)

[14] www.arduino.cc/en/Main/Software, (Erişim tarihi: 09.03.2017) 